\title{
El Parque Natural del Alto Tajo de la provincia de Guadalajara (España) 2000-2013. Balance y perspectivas
}

\author{
Alejandro LÓPEZ LÓPEZ \\ lopezal@pdi.ucm.es
}

Recibido: 21 de mayo de 2013

Enviado a evaluar: 4 de junio de 2013

Aceptado: 3 de octubre de 2013

\section{RESUMEN}

El presente artículo ofrece una reflexión sobre la interdependencia entre el espacio natural protegido, el ecosistema social (36 municipios del Parque), el desarrollo sostenible del turismo y la preservación de los impactos ambientales, especialmente los incendios forestales.

Palabras clave: Espacio natural protegido, recursos hídricos, gestión del territorio, desarrollo turístico sostenible y calidad de vida.

\section{The Alto Tajo Natural Park in the province of Guadalajara (Spain) from 2000 to 2013. Balance and perspectives}

\begin{abstract}
This article is a reflection on the interdependence between the conservation area, the social ecosystem (36 municipalities in the Park), sustainable development of tourism and the preservation of environmental impacts, especially forest fires.
\end{abstract}

Key words: Protected Natural Area, Water resources, Land management, Sustainable tourism development and quality of life.

\section{Le Parc Naturel Alto Tajo dans la province de Guadalajara (Espagne) de 2000 à 2013. Bilan et perspectives}

\section{RÉSUMÉ}

Cet article est une réflexion sur l'interdépendance entre la zone de conservation, l'écosystème social (36 communes du Parc), le développement durable du tourisme et la préservation des impacts environnementaux, en particulier les incendies de forêt.

Mots-clés: Zone naturelle protégée, Ressources hydriques, Gestion du territoire, Développement du tourisme durable et qualité de vie. 


\section{INTRODUCCIÓN}

De los 7 principales ríos de la Península Ibérica, el Río Tajo es el primero por su longitud: 1.010 kilómetros, de los cuales 713 pertenecen a territorio español y el resto a Portugal.

Nace en la Muela de San Juan, en el término municipal de Frías (Teruel) a una altitud de 1.610 metros, en la confluencia de las provincias de Teruel, Cuenca y Guadalajara. Recibe varios afluentes que para el objeto de esta Ponencia solo cabe citar los de Oceseca y Gallo. Posteriormente el almacenamiento de su agua se produce en la gran presa de Bolarque y en los pantanos de Entrepeñas y Buendía (para el Trasvase Tajo-Segura que se inauguró en 1979 siendo Ministro de Obras Públicas Joaquín Garrigues Walker).

Dicho esto, hay que añadir que la precipitación media de la cuenca del Tajo ha sido de $648 \mathrm{~mm}$ en el periodo 1940-2006, ligeramente inferior a la media nacional. La cuenca del Tajo alberga a 7 millones doscientos mil habitantes en 107 municipios de más de 5.000 habitantes, incluyendo a la ciudad de Madrid con 3.233.527.

Pero aquí y ahora lo que se trata es de reflexionar sobre el territorio con sus ecosistemas naturales, y sobre todo, con sus ecosistemas sociales que componen el tantas veces demandado Parque Natural del Alto Tajo.

En efecto, ;por fin! en la primavera del año 2000 fue declarado Parque Natural del Alto Tajo el territorio de la provincia de Guadalajara desde sus puertas orientales (municipios de Alustante y Orea) hasta las occidentales representadas por los municipios de Zaorejas y Villanueva de Alcorón, con un total de 36 municipios, todos afectados por la emigración de los años 60 pero que se mantienen en pie - no sin dificultades- con una densidad de población de algo más de 2 habitantes por kilómetro cuadrado en la época del invierno.

Este artículo fue presentado, en parte, como Ponencia en el Simposio Internacional "Gestión del Territorio: recursos hídricos y espacios naturales", que tuvo lugar en la Hospedería del Parque Nacional de Monfragüe (Extremadura) durante los días 17, 18 y 19 de abril de 2013.

Comprende el Parque Natural, entre el Parque (105.000 hectáreas) y el Pre-Parque, una superficie de 176.000 hectáreas, dominadas por bosques de coníferas: pinares y sabinares, frondosas y matorrales, sobre parameras, hoces y cañones de la cabecera de la cuenca del Río Tajo de un gran valor ecológico, paisajístico y cultural.

En el Parque Natural del Alto Tajo podemos encontrar grandes extensiones de naturaleza en su estado más salvaje y, a su vez, zonas transformadas armónicamente por el hombre, que son reflejo del respeto con que sus habitantes han desarrollado los usos tradicionales, de forma compatible con la conservación de los valores naturales de la zona. El Río Tajo, con sus afluentes, vertebra este espacio natural, incidiendo sobre la paramera caliza y creando el sistema de cañones y hoces fluviales más extenso de la Península Ibérica.

José Luis Sampedro, en su novela El río que nos lleva, retrata de forma certera el alma de estos parajes naturales y de sus habitantes, especialmente el oficio de los "gancheros". 
Figura 1. Mapas de localización

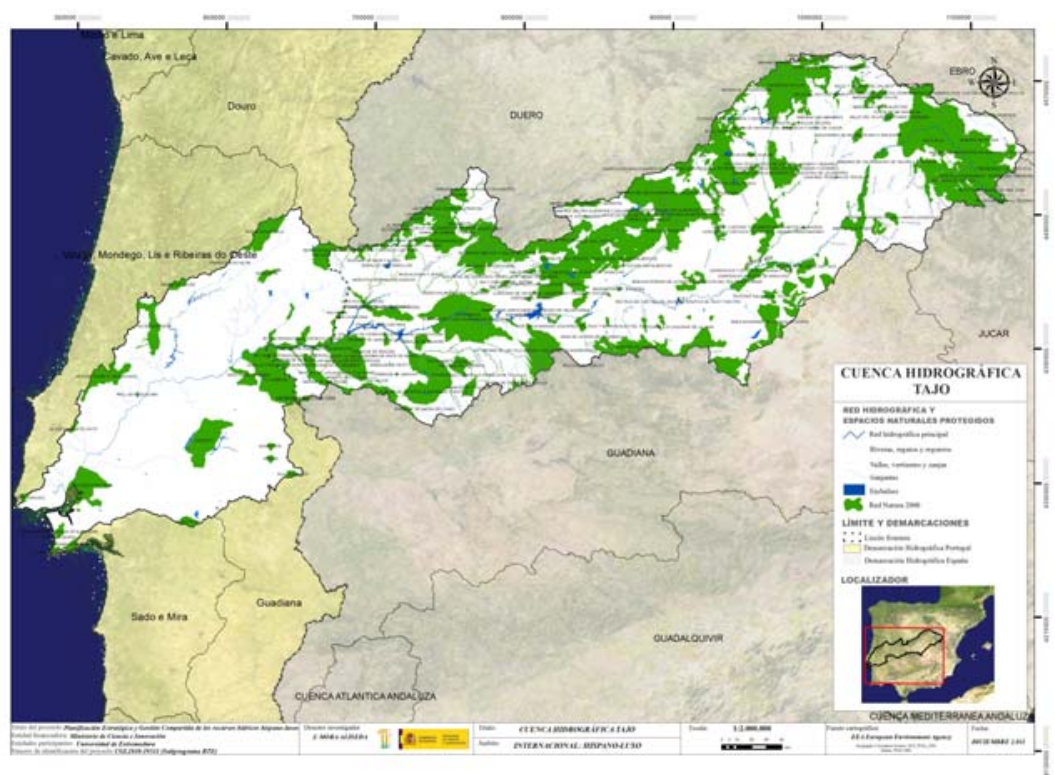

Fuente: Mora Aliseda, Julián (2013)

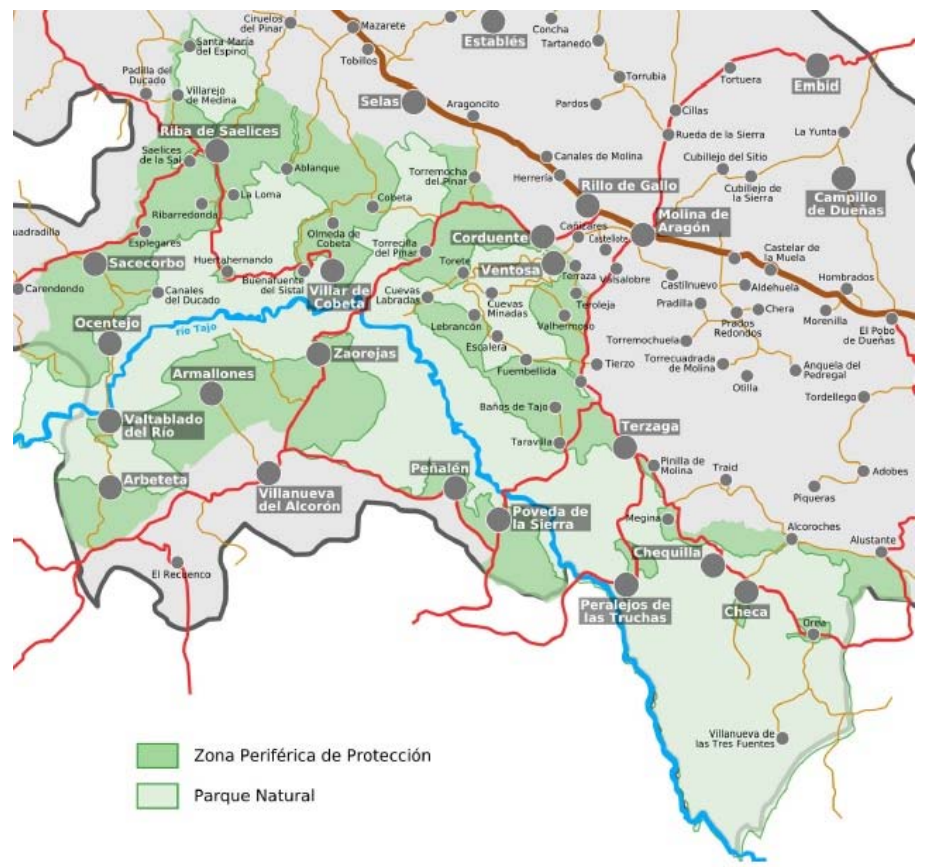

Fuente: www.turismomolinaaltotajo.com 


\section{LA HISTORIA DEL PARQUE NATURAL DEL ALTO TAJO (2000-2013)}

Para bien o para mal, el Parque Natural se ha visto ligado desde su creación al debate hidrológico entre los políticos de Castilla-La Mancha, Murcia y Valencia, además del Gobierno central de Madrid.

Como ha puesto de manifiesto Ramón Tamames (La Razón 24 de marzo 2013, pág. 15) el crecimiento demográfico de la población humana y sus nuevas necesidades de desarrollo están produciendo una demanda mayor de agua en distintos territorios de nuestro mundo que pueden plantear "las guerras del agua" en diversos escenarios del planeta Tierra. Se citan varios casos, desde las aguas de los Altos del Golán, en Oriente Próximo, hasta el macizo del Tíbet. Lo cual plantea la acuciante necesidad de encauzar potenciales conflictos cuando hoy todavía son posibles acuerdos razonables.

En el tema central que aquí nos ocupa, sólo alejando el agua de la arena política y pasando, como hoy se nos invita, de la confrontación (Declaraciones, Prensa, Tribunales de Justicia y Tribunal Constitucional, Parlamento de la Nación y guerra entre Comunidades Autónomas) a la cooperación se conseguirá la solución al zarandeado Trasvase Tajo-Segura.

La firma del documento de consenso presentado por el ministro Cañete con el denominado "Memorándum" puede ser el primer paso hacia el cambio de legislación, ya que la declaración de intenciones para su efectividad tiene que aprobase como Ley española en las Cámaras Legislativas del Congreso y del Senado. Esperamos que, aunque tarde, se consiga este éxito después de tanto tira y afloja de índole políticopartidista y de intereses económicos.

Las expectativas con las que se aprobó el Parque el 6 de abril del año 2000, se han cumplido en algunos aspectos que enumeraré a continuación:

1) Mejora de las infraestructuras por carretera (la distancia tanto desde Madrid como desde Valencia supera ligeramente los 200 kilómetros).

2) Creación de 4 Centros de Interpretación y Educación Ambiental:

-Corduente

-Orea

-Checa

-Zaorejas

3) Continuación y consolidación de la Fiesta de los Gancheros que en 2013 tendrá lugar la celebración de la XVII edición, el 31 de agosto en Peralejos de las Truchas.

4) Instalación, diseño y señalización de 14 rutas de la naturaleza dentro del Parque. 
5) Un número de 40 instalaciones recreativas de uso público distribuidas equilibradamente en el territorio.

6) Colocación de paneles -aunque insuficientes y sin estrategia adecuada- con el mapa del Parque Natural.

7) Se han multiplicado y subvencionado las casas rurales, restaurantes y otra serie de actividades relacionadas con el turismo, gracias a los programas LEADER de la Unión Europea desde 1991.

8) En algunos municipios se ha apostado por la cultura popular y la participación ciudadana en fiestas y conmemoraciones tradicionales y de nuevo sello (p. ej. de carácter ecológico).

9) Existen revistas periódicas (3 al año como HONTANAR de Alustante) modélicas en su género.

10) Se están recuperando el urbanismo tradicional y la gastronomía serrana y molinesa.

11) Desde hace cinco años la comarca dispone de una central de biomasa ubicada en el término de Corduente, que en teoría debería servir para vehicular los residuos forestales de la gran masa arbórea del Parque Natural.

\section{TEMAS PARA DEBATE Y PLANIFICACIÓN TERRITORIAL}

\section{a. La vegetación dominante: el pino silvestre}

La vegetación se caracteriza por una rica variedad de especies, entre ellas los encinares y quejigares, la sabina de porte y la sabina rastrera, pero por encima de toda destacan los pinares (pino rodeno, pino negral o laricio y el pino silvestre).

El conjunto de la vegetación del Parque Natural constituye una riqueza ecológica de primera magnitud, tanto por ser una de las masas forestales más importantes de la península como por contribuir decididamente al descenso de la contaminación y del cambio climático, disponiendo desde el punto de vista del paisaje un valiosísimo "azul velazqueño".

Desde una perspectiva histórica basta recordar su importancia maderera y ganadera, cuyas expresiones máximas estuvieron representadas por los transportadores gancheros -desde el Alto Tajo hasta Aranjuez- y por la utilización por parte del rey Felipe II para la construcción de la techumbre del Monasterio de El Escorial, con pinos extraídos de los municipios de Alustante y Checa.

Recientemente, por el turismo mal controlado y por la perniciosa afición al empleo del fuego, hemos sufrido dos grandes incendios forestales. En efecto, a mediados de julio de 2005 tuvo lugar el incendio forestal de Riba de Saelices en la parte occidental 
del Parque, con el trágico resultado de 11 personas fallecidas y 13.000 hectáreas calcinadas.

En el verano de 2012 en el pequeño municipio y más pintoresco del Parque, en Chequilla, asistimos al segundo embate contra la naturaleza, las personas y el paisaje, la rápida reacción impidió otro gran desastre ecológico y humano.

En definitiva, existen carencias en el sistema de vigilancia, en la dotación de un pequeño destacamento de bomberos dentro del propio Parque, y no a 50 kilómetros, en Molina de Aragón, y, finalmente, campañas continuadas de Educación Ambiental.

\section{b. Plan de dinamización turística del Alto Tajo}

Siguiendo la práctica positiva y original de los Planes españoles de dinamización y de excelencia turística, iniciados en 1992, a tres bandas entre Ayuntamientos, Comunidades Autónomas y Secretaría de Estado de Turismo, es hoy tan urgente como lo era ya desde el año 2000. Pero aún es un déficit económico-político-administrativo.

Solamente con un turismo sostenible estaremos en condiciones de respetar la naturaleza y promover el progreso de la población que reside durante todo el año en el Parque.

\section{c. Sanidad cercana a todos los pueblos}

Funcionando al servicio de los ciudadanos las 24 horas del día (los dos centros) y continuando el sistema de visitas y atención a todos los municipios de menor entidad. No hay que olvidar que el mayor porcentaje de la población está prácticamente en la franja de la tercera edad, como residentes durante todo el año y de los visitantes y turistas en tiempo de vacaciones.

\section{d. Educación}

Salvaguardar las escuelas rurales del Alto Tajo y seguir con el sistema heredado aunque se introduzca mayor racionalidad y menor coste, pero nunca cerrando escuelas y obligando a los alumnos al trasiego de viajes, autobuses y riesgos.

\section{e. Agua para todos}

Admitiendo y proponiendo la cooperación en materia de agua como se ha manifestado al principio de esta Ponencia, es imprescindible y exigible que a los pueblos de la Cabecera del Tajo no se los abandone a su suerte en el suministro de agua potable para los hombres y mujeres, ni tampoco para los ganados y la pequeña agricultura a casi 1.500 metros de altitud con un clima continental mediterráneo. 


\section{CONCLUSIONES}

$1^{\text {a }}$ : Mantenimiento del régimen de aprovechamientos madereros, de pastos y micológicos.

$2^{\mathrm{a}}$ : Conservación y repoblación con especies autóctonas.

$3^{\mathrm{a}}$ : Defensa de la naturaleza como se ha hecho durante siglos por los ganaderos y agricultores mediante las buenas prácticas agrícolas y ganaderas.

$4^{\mathrm{a}}$ : Declaración de guerra al fuego en el monte y en las superficies rústicas.

$5^{\text {a }}$ : Creación de aparcamientos disuasorios.

$6^{\text {a }}$ : Potenciación del desarrollo endógeno mediante la recuperación de productos ecológicos y de denominación de origen tal como propone la Red Natura 2000 de la Unión Europea, agricultura y ganadería ecológicas.

$7^{\text {a: }}$ Aprobación en los 36 municipios de las Normas Subsidiarias de Urbanismo, respetando las características tradicionales y el buen gusto de las viviendas utilizando la madera, la piedra y la forja tradicionales y autóctonas en la rehabilitación y en la construcción de nuevas viviendas, naves industriales y ganaderas.

$8^{\text {a }}$ : Inversión y gestión compartida entre los empresarios, ganaderos y los ayuntamientos mediante la explotación de aproximadamente 10.000 ovejas como factor de conservación del Parque y de prevención de incendios forestales.

$9^{\text {a }}$ : Campañas de información y de Educación Ambiental a los visitantes, turistas y lugareños como factores de tratamiento respetuoso de Medio Ambiente y de prevención de incendios.

$10^{\text {a }}$ : Potenciación, uso y planificación de los cuatro centros de interpretación ambiental del Parque Natural: Orea, Checa, Corduente y Zaorejas.

\section{BIBLIOGRAFÍA}

AEMA (2010). Los recursos del agua en Europa: cómo hacer frente a la escasez del agua y la sequía. Ed. Ministerio de Medio Ambiente, Medio rural y marino. Madrid, 55 páginas.

A.A.V.V. (2001). El Tajo, destino de ríos y hombres. AGESMA Ediciones. Toledo.

A.A.V.V. (2006). Mapa forestal de España. Provincia de Guadalajara. Escala 1:50.000 CD-ROM.

BOLETÍN INFORMATIVO del Parque Natural del Alto Tajo, $\mathrm{N}^{\circ}$ 7, octubre 2009, pág. 11: El Parque Natural recibió el Certificado de adhesión a la Carta Europea de Turismo Sostenible (CETS) 12 septiembre, en la Conferencia EUROPARC, en Strömstad (Suecia).

BORRELL MERLÍN, M. D. (2013). El Tajo, Parque y Cultura, en Hontanar, Boletín de la Asociación Cultural de Alustante (Guadalajara) No 59, págs. 26 y 27.

DE LORENZO, P. (2003). Viaje de los ríos de España: Tajo y Segura. Edición Biblioteca extremeña. Badajoz, 103 páginas.

GÓMEZ, R., DEL PALACIO, M. y SÁNCHEZ SEGURA, T (2005). Un ejemplo de abastecimiento y saneamientos a ciudades. La Confederación Hidrográfica del Tajo, en Observatorio Medioambiental Nº 8 Madrid, págs. 127-151. 
GÓMEZ OREA, D., RUBIO BLANCO, D. (2000). Plan de ordenación de los recursos naturales y desarrollo sostenible del Alto Tajo. Observatorio Medioambiental №3, año 2.000, págs. 159-194.

LA ROCA, Francesc, FERRER, Graciela (2007). La economía en el desarrollo de la Directiva Marco del Agua, en REV. Observatorio Medioambiental No 10. Madrid 2007 págs. 179-198.

LAMO DE ESPINOSA, Jaime (2013). Joaquín Costa: agricultura, economía y política hidráulica. Ediciones EUMEDIA. Madrid, 95 págs.

LARRAZ IRIBAS, Beatriz- CANO SAAVEDRA, Alejandro (coordinadores) (2013). El río Tajo, lecciones del pasado para un futuro mejor. Editorial LEDORIA, Toledo, 308 páginas.

LÓPEZ LÓPEZ, Alejandro (1983). Ecosistema Social y Medioambiente, en A.A.V.V.: Sociología y Medioambiente. Ed. Ministerio de Obras Públicas y Urbanismo, Madrid, págs. 43-59

LÓPEZ LÓPEZ, Alejandro (1999). El futuro del Parque Natural del Alto Tajo, en Revista del Decano de Guadalajara, 20 de abril de 1999.

LÓPEZ LÓPEZ, Alejandro(2006). La fiesta de los Gancheros: una tradición histórica, natural y cultural en el Alto Tajo, en revista HONTANAR, Boletín de la Asociación Cultural de Alustante, Guadalajara, pág. 7.

LÓPEZ LÓPEZ, Alejandro (2011). Recursos hídricos y desarrollo sostenible: requisitos para la planificación y gestión compartida entre España y Portugal. Observatorio Medioambiental No 14 , págs. 157-175.

LÓPEZ LÓPEZ, Alejandro (2011). Invitación a la Educación Ambiental: recursos hídricos, desarrollo sostenible y gestión compartida. Ed. Asociación Española de educación Ambiental, Granada-Madrid, 36 páginas.

LÓPEZ LÓPEZ, Alejandro, SANZ MARTÍNEZ, Diego, ESTEBAN LORENTE, Juan Carlos (2012). Alustante paso a paso. Ed. AACHE, Guadalajara, 246 páginas. Véanse págs. 164-169.

LÓPEZ LÓPEZ, Alejandro (2013). El río que nos lleva: homenaje a José Luis Sampredro. En Tribuna Complutense, Madrid, Pág. 10.

LÓPEZ VÁZQUEZ, Luis (2010). El Alto Tajo. Guía del Parque Natural. Ed. El Senderista, Madrid, $4^{a}$ edición, 263 páginas.

MORA ALISEDA, Julián. Red hidrográfica y espacios naturales protegidos. Ámbito internacional hispano-luso. Ministerio de Ciencia e Innovación.

MORA ALISEDA, Julián, y DOS REIS CONDESSO, Fernando (2005). Políticas urbanas y territoriales en la Península Ibérica. 2 vols. Editora regional de Extremadura. Badajoz.

SAMPEDRO, José Luis (2012). El río que nos lleva. Ed. Mondadori. Barcelona, 405 páginas.

SOTELO NAVALPOTRO, José Antonio (2001). Plan Hidrológico vs Plan Hidrológico Nacional, Observatorio Medioambiental, №4 Madrid, págs. 13-16.

SOTELO NAVALPOTRO, José Antonio (2004). El hombre y el medio, en el libro Cincuenta años de la Confederación Hidrográfica del Tajo. Coordinado por Flores 
Montoya, Javier. Edición de la Confederación Hidrográfica del Tajo. Madrid, Págs. 23-43

SOTELO NAVALPOTRO, José Antonio. Espacios y sociedades, en el libro Cincuenta años de la Confederación Hidrográfica del Tajo, Págs. 217-249

SOTELO NAVALPOTRO, José Antonio et alii (2011) Huella hídrica, desarrollo y sostenibilidad en España. Fundación MAPFRE, Madrid, 425 páginas.

VALENZUELA MONTES, L. M., MATARÁN RUIZ, A. (2007). Criterios $e$ indicadores para la formulación de un Observatorio de Desarrollo Territorial de las relaciones entre agua, agricultura y paisaje, en Observatorio Medioambiental №10 Madrid, 2007 págs. 243-263.

\section{BIBLIOGRAFÍA (PRENSA DIARIA)}

CABRERA, Enrique: "La otra burbuja, la del agua" El País, 22 de marzo de 2013 págs. 29-30.

DEL CASTILLO, Leticia: "El Parque Natural del Alto Tajo recibió a más de 40.000 visitantes en el año 2008". En Nueva Alcarria (Guadalajara), lunes 9 de febrero de 2009. Página 10.

ELVIRA, A: "Ovejas, vacas y cabras antiincendios". LA RAZÓN, domingo 7 de abril de 2013, página 56.

E.M. "El Plan Hidrológico del Tajo endurece el trasvase". La Razón 21 marzo 2013, pág. 42.

FERRER, Thiago: "Presente y futuro del agua potable". EL PAÍS, 14 de abril de 2013. Sección Negocios. Páginas 18 y 19.

GÓMEZ MENDOZA, Josefina: "Los montes públicos, ¿a la venta?” El País, 20 de marzo de 2013, pág. 33.

GONZALEZ, A y MARTíNEZ, D.: "El Plan Hidrológico del Tajo endurece las condiciones para trasvasar al Segura. "El borrador fija una reserva estratégica en cabecera de 400 hectómetros y un caudal mínimo de 10 metros cúbicos por segundo en Toledo y Talavera. ABC 21 marzo 2013, pág. 40.

LAPUENTE, Enrique: "La desalación en el Plan del Tajo". EL PAÍS, sábado 27 de abril de 2013, página 31.

LA RAZÓN (Suplemento) "Día Mundial del Agua, entre la escasez y su mal aprovechamiento" 22 marzo 2013.

MARTÍ, A-CLEMENTE, J.: "El trasvase Tajo-Segura, blindado". Un acuerdo entre Valencia, Murcia y Castilla-La Mancha garantiza el agua del río Segura. La Razón, 23 marzo 2013 págs. 38 y 39.

MÉNDEZ, Rafael: “Todos ceden”, El País 21 marzo 2013, pág. 38.

RULL Eva M.: "Cooperación en agua". España instala la primera planta de fitodepuración de Vietnam. La Razón, 24 marzo 2013, pág. 14.

TAMAMES, Ramón: “Hidrohostilidades” La Razón 24 marzo 2013, página 15. 


\section{ANEXOS}

A) Ley 1/2000, de 6 de abril, por la que se declara el Parque Natural del Alto Tajo DOCM núm. 43 (05/05/2000) BOE núm. 159 (04/07/2000)

\section{EXPOSICIÓN DE MOTIVOS}

El Plan de Ordenación de los Recursos Naturales del Alto Tajo, aprobado mediante Decreto 204/1999 de 21 de septiembre y publicado en el Diario Oficial de Castilla-La Mancha núm. 61 de 24 de septiembre de 1999, prevé el establecimiento de la figura de protección de Parque Natural para un amplio territorio de $\mathbf{1 0 5 . 7 2 1}$ hectáreas que se extiende por 35 términos municipales de la provincia de Guadalajara y $\mathbf{2}$ de la provincia de Cuenca, en aplicación de lo dispuesto por el artículo 41 de la Ley 9/1999, de 26 de mayo, de Conservación de la Naturaleza.

Este área constituye el sistema de hoces fluviales más extenso de la Región, en el que una gran diversidad geológica, climática y topográfica, unida a un excelente grado de conservación de los ecosistemas naturales, configuran un espacio natural de excepcional importancia desde el punto de vista de la conservación de la biodiversidad y el paisaje de Castilla-La Mancha. Valga como indicador que en la zona se ha apreciado la existencia de más de 110 lugares de importancia geomorfológica, más de 100 microhábitats de interés florístico, y de al menos 69 especies de flora y 129 de fauna vertebrada incluidas en el Catálogo Regional de Especies Amenazadas aprobado por el Decreto 33/1998.

Adicionalmente, se ha puesto de manifiesto su importancia para la conservación de varias especies amenazadas de aves incluidas en el anexo I de la Directiva 79/409/CEE, relativa a la protección de las aves silvestres, así como para numerosos hábitats y taxones incluidos respectivamente en los anexos I y II de la Directiva 92/43/CEE, relativa a la conservación de los hábitats naturales, y de la flora y fauna silvestres, configurándose este espacio natural como un área importante para la conservación de la biodiversidad de la Unión Europea, susceptible de formar parte de la Red NATURA 2000.

Dicho Plan de Ordenación se ha aprobado por el Consejo de Gobierno con los objetivos específicos de asegurar la conservación de los valores naturales más significativos del Alto Tajo, procurar su restauración cuando se encuentren degradados, fomentar los aprovechamientos tradicionales y el turismo de naturaleza, y sentar las bases de un desarrollo sostenible.

La presente Ley viene a sustanciar la aplicación del régimen de protección previsto en el Plan de Ordenación para el territorio propuesto como Parque Natural. Así, establece el régimen aplicable a los usos, aprovechamientos y actividades, el mandato de elaboración de un Plan Rector de Uso y Gestión, crea una Junta Rectora como órgano consultivo y la figura del Director-Conservador.

Complementariamente, como consecuencia de las previsiones del Plan de Ordenación, se establece una Zona de Influencia Socioeconómica, para la que será de aplica- 
ción un Plan de Desarrollo Sostenible que facilite la consecución de los objetivos sociales establecidos en paralelo a los de conservación de la naturaleza, y en particular para contribuir a generar empleo, fijar población en la zona, fomentar la funcionalidad de la estructura territorial, impulsar la cohesión comarcal, promocionar la calidad como guía del desarrollo y fomentar la promoción externa del Parque Natural y su Área de Influencia Socioeconómica.

El Decreto 204/1999 también inicia el procedimiento de declaración del Parque Natural del Alto Tajo. En el expediente seguido para la aprobación del Plan de Ordenación de los Recursos Naturales del Alto Tajo, del que es consecuencia esta declaración, ya se otorgó audiencia a los interesados y se realizaron los trámites de información pública y consulta a los intereses sociales e institucionales afectados. Por aplicación del artículo 32.4 de la citada Ley 9/1999, no es preciso reiterar dichos trámites en el procedimiento de aprobación del Proyecto de Ley de declaración del Parque Natural.

Tal como requiere el artículo 32.2 de la ley 9/1999, el Proyecto de Ley ha sido sometido a informe del Consejo Asesor de Medio Ambiente.

La presente Ley se redacta en aplicación de las competencias de desarrollo legislativo y de ejecución que el artículo 32 del Estatuto de Autonomía de Castilla-La Mancha atribuye a esta Administración Autónoma en las materias de espacios naturales protegidos y de protección del medio ambiente y los ecosistemas; de conformidad con lo dispuesto en la Ley 9/1999, de 26 de mayo, de Conservación de la Naturaleza, y de conformidad con el dictamen del Consejo Consultivo. 